\title{
Longitudinal Relationship between Gratitude and Benign/Malicious Envy: Evidence from a Cross-Lagged Analysis
}

\author{
Liying Zhang and Lijun Yang \\ School of Educational Sciences, Hunan Normal University, Changsha, 410081, China \\ *Corresponding Author: Lijun Yang. Email: yanglj7291@163.com \\ Received: 07 August 2021 Accepted: 27 October 2021
}

\begin{abstract}
Though prior research has identified that gratitude is associated with benign/malicious envy (BeMaS). The purpose of this study was to explore the causal relationship between gratitude and BeMaS among Chinese adolescents. The two-wave study, in which 906 adolescents participated, includes measurements of gratitude and BeMaS. We employed the structural equation models to test the cross-lagged effect between trait gratitude and BeMaS. The results showed that gratitude could positively predict benign envy and could negatively predict malicious envy. Besides, there was no evidence for the reverse or reciprocal relationships between gratitude and BeMaS. The findings provide further evidence about the causal relationship between gratitude and BeMaS among adolescents. Moreover, these results have implications for gratitude interventions that promote the constructive meaning of envy and reduce the negative influence of envy.
\end{abstract}

\section{KEYWORDS}

Cross-lagged analysis; gratitude; benign envy; malicious envy

\section{Introduction}

With positive psychology booming, researchers have focused on trait gratitude [1-3]. Trait gratitude is a positive outlook, which refers to an orientation to notice the positive outcomes that one obtains [4]. Trait gratitude positively affects the well-being of adolescents, such as life satisfaction and positive affect [5]. In addition, trait gratitude is associated with less negative emotion, such as envy [6]. What's more, recent research points out that there are two types: benign envy has a constructive significance, while malicious envy is related to destruction $[7,8]$. However, little research has examined the causal link between gratitude and envy, let alone the causal link between gratitude and two types of envy among adolescents. Given all this, based on the broaden-and-build theory, the present study aimed to explore the causal relationship between gratitude and two types of envy among adolescents from a longitudinal perspective. At the same time, the cross-lagged study can enrich the research of gratitude and envy and find appropriate interventions that reduce the negative influence of envy, and improve well-being among adolescents.

Based on the broaden-and-build theory, gratitude may be an antecedent of benign/malicious envy. The broaden-and-build theory asserts that positive emotions such as gratitude can develop the breadth of instant thought and action, and build personal resources: from physical and intelligent resources to mental and social resources [9]. On the one hand, gratitude can broaden the cognitive horizon and help individuals build 
positive emotions or attributes. For instance, Tian et al. [10] have discovered, grateful people were inclined to feel more positive emotions, leading to more positive evaluations of their environments. On the other hand, gratitude helps to build abundant personal resources. For example, gratitude can construct resilience and social support $[11,12]$. In short, gratitude benefits individuals from the higher level of self-assessment and more personal resources, which may further lead to a higher sense of control in upward social comparison, and then triggers a high frequency of benign envy rather than malicious envy [13]. Therefore, in upward social comparison, individuals with high gratitude may generate more benign envy, less malicious envy. In addition, some correlation studies have found that gratitude is positively related to benign envy and negatively related to malicious envy $[14,15]$. Therefore, this study proposed the first hypothesis is the following: Preceding gratitude may positively predict following benign envy, while negatively predict later malicious envy.

Furthermore, benign envy and malicious envy may be the antecedents of gratitude. From an evolutionary perspective, envy is regarded as an innate human tendency and ability [16]. Therefore, envy as an inborn emotion may have a gigantic impact on the change of gratitude. For example, as Klein [17] emphasized, envy makes people pay attention to what he lacks, distracts the individual from focusing on or being pleased about the blessings he does own, which might hold back gratefulness. Previous studies have confirmed the robust inverse relationship between envy and gratitude [6,18,19]. In addition, Solom et al. [20] used a prospective design and found that after controlling for initial levels of gratitude, Time 1 envy had a negative predication on Time 2 gratitude. Thus, envy may inhibit gratitude. In addition, two types of envy may have diverse effects on gratitude. For one thing, benign envy may lead to gratitude, such as appreciating the envied who practically situates higher positions [7]. Besides, individuals with higher levels of benign envy were more likely to show high self-esteem [21], which causes people to appreciate the positive outcomes that they obtain [22]. For another, malicious envy may inhabit gratitude. Individuals with malicious envy present higher narcissism in daily life [23], and they regard most benefits as things they are entitled to and cause a low level of grateful [24]. Thus, considering the evidence mentioned above, we proposed Hypothesis 2 in the following: Prior benign envy might positively predict subsequent gratitude, prior malicious envy might negatively predict succeeding gratitude.

The present study would extend prior work in the following ways. First, the existing studies on the relationship between gratitude and benign/malicious envy are almost all cross-sectional studies. What's more, cross-sectional studies cannot test the causal relationship between variables. Therefore, this research adopts a longitudinal study that helps comprehensively understand the predictive causality effect between them. Second, given that adolescents experience major physical and psychosocial changes with rapid growth and development [25], testing the predictive causality effect between gratitude and benign/malicious envy would provide new knowledge about well-being in the period. Third, our cross-lagged study would contribute to finding interventions that exert the constructive function of envy from the perspective of positive psychology.

In conclusion, the current study would examine the predictive causality link between gratitude and the two types of envy through a longitudinal study in Chinese adolescents.

\section{Method}

\subsection{Participants and Procedure}

Participants were 906 students aged 8 to 15 years (Mage $=11.20$ years, SD $=1.65$ years, 444 males and 462 females, 452 pupils, and 454 junior school students) who were recruited from one primary school and two junior high schools in China. The study is a longitudinal tracking study, so when sampling, we mainly considered those schools that are interested in this project, and finally determined the three schools that are interested in the tracking plan of this project.

The current study used a longitudinal design. Through cluster sampling, participants in two junior high schools and one primary school were recruited in Hunan Province, China. At Time 1 (T1) 937 students of 
Grades 4th, 5th, 7th, and 8th participated in this study. After one year's interval, these students were asked to finish the same questionnaires at Time 2 (T2). After deleting the missing data (some students were sick, transferred, and dropped out) or data with erroneous ID information, finally, a total of 906 valid samples were obtained. The sample attrition rate is $3.30 \%$, which is negligible. All participants volunteered for the present study and signed informed consents before the study. Then they completed all questionnaires in the classroom at the same time with the help of the school. The ethical principles of the research have been approved by the Academic Committee of the School of Psychology of Hunan Normal University.

\subsection{Measures}

\subsubsection{Dispositional Gratitude}

Gratitude was evaluated by the GQ-6 [4] The scale includes six items (e.g., 'I feel pleased for what I have obtained in life'), and each item is evaluated on a 7-point Likert scale (1, strongly disagree; 7, strongly agree). It has been supported that the Chinese version of the GQ-6 has acceptable reliability and validity [26,27]. To explore whether the questionnaire applies to primary school students and junior high school students, we conducted a confirmatory factor analysis. The results showed a good fit in primary school students $\left(\chi_{(9,906)}^{2}=19.674, p<0.001, \mathrm{RMSEA}=0.051, \mathrm{SRMR}=0.032, \mathrm{CFI}=0.978, \mathrm{NNFI}=0.960\right)$ and junior high school students $\left(\chi_{(9,906)}^{2}=42.437, p<0.001\right.$, RMSEA $=0.064$, SRMR $=0.050, \mathrm{CFI}=0.939$, NNFI $=0.924$ ). The Cronbach alpha coefficients of the GQ-6 were 0.71 in primary school students and 0.71 in junior high school students. In the existing research, the Cronbach alpha coefficients of the GQ-6 were 0.66 at $\mathrm{T} 1$ and 0.71 at $\mathrm{T} 2$.

\subsubsection{Benign Envy and Malicious Envy}

The 10-items Benign and Malicious Envy Scale was utilized to estimate benign envy and spiteful envy (BeMaS) [28]. The BeMaS is a 6-point gradation from 1 "strongly disagree" to 6 "strongly agree", consisting of 5 items for BE (benign envy) and 5 items for ME (malicious envy). Example items include "Envying others encourages me to finish my purposes" for surveying BE and "I wish that better people forfeit their advantage" for weighing ME. The Chinese version of the BeMaS has acceptable reliability and validity in Chinese college students [27,29] and Chinese adolescents [30]. In the present examination, the Cronbach alpha index of $\mathrm{BE}$ and $\mathrm{ME}$ subscale were 0.71 and 0.85 at $\mathrm{T} 1$, and 0.82 and 0.84 at $\mathrm{T} 2$, respectively.

\subsection{Data Analysis}

We employed SPSS 21.0 and Amos 24.0 to dissect the obtained statistics. Firstly, a correlation examination was adopted to inspect the associations among the hidden variables using SPSS 21.0. Secondly, in order to explore the link between characteristic gratitude and BeMaS, we made use of constructional equation mold procedure to calculate a cross-lagged model between feature gratitude and BeMaS using Amos 24.0. Specifically, four conflicting constructional equation models were constructed to explore the causal link between feature gratitude and BeMaS (see Fig. 1).

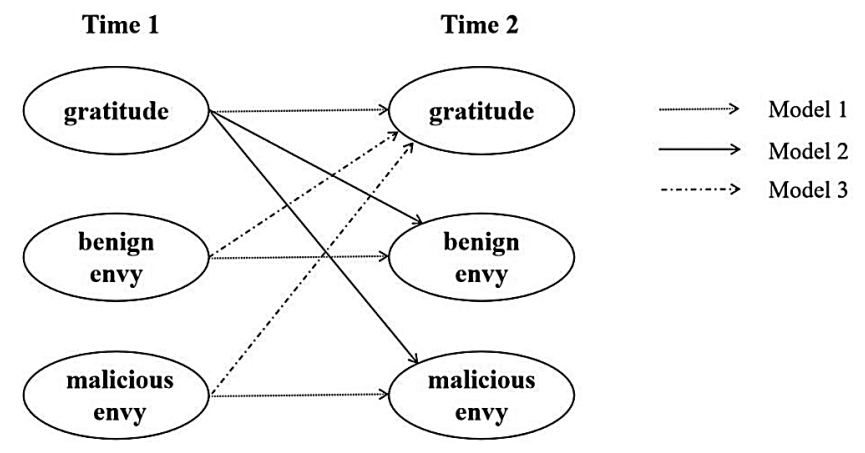

Figure 1: Cross-lagged sorts between feature gratitude and BeMaS 
Model 1 as a reference line model, was a representative autoregressive model without cross-lagged effect. Temporary permanence of the variable over time was revealed by the model. Based on Model 1, a standard causality model (Model 2) was established. In the model, cross-lagged routes from peculiarity gratitude at Time 1 to $\mathrm{BE}$ at Time 2 and ME at Time 2 were added. Furthermore, based on Model 1, a contrary causation model (Model 3) was also confirmed. The Model 3 extended Model 1 by putting in cross-lagged routes from BE at Time 1 and ME at Time 1 to trait gratitude at Time 2. Finally, we created a mutual causation model (Model 4) in which all autoregressive and cross-lagged routes from Model 1 to Model 3 were involved.

The total fit of four models were estimated by a series of good-of-fit indexes: Tucker-Lewis indicatrix (TLI), comparative fit indicatrix (CFI), standardized root mean square residual (SRMR) and root mean square error of approximation (RMSEA). If TLI and CFI are bigger than 0.90, SRMR and RMSEA are littler than 0.08 , the model is believed to fit well [31]. $\chi^{2}$ was also described, but not employed to gauge the fit of the four models because of its great susceptibility to the size of sample [32].

\section{Results}

\subsection{Common Method Biases Analysis}

In this survey, variables were measured by a self-report technique, so there might occur a common technique biases effect. Thus, necessary controls were employed during the data collection process. For example, researchers emphasized the confidentiality of research data to the participants. In addition, we also carefully examined whether common method biases effect existed by Harman's single-factor inspection [33]. The results found that 4 factors with characteristic root greater than 1 in both measurements, and the eigenvalue of the first factor were $29.84 \%$ at the first measurement and $29.72 \%$ in the second measurement. Therefore, there was no severe common technique bias outcome in this study.

\subsection{Effect Size and Repeated Measures Analysis of Variance}

First, the effect sizes of the subjects' gratitude and benign/malicious envy were examined. Second, a $2 \times$ 2 (time $\times$ gender) repeated measures testing of variance was made on the variables (see Table 1 ). The results presented that the effect sizes of gratitude and malicious envy were small, and the proportion of nonrepetition was less than $14.7 \%$. The effect size of benign envy was intermediate in the two measurements, and the proportion of non-repetition ranged from $14.7 \%$ to $33.0 \%$. In addition, no gender difference was found in gratitude, benign envy, and malicious envy. Therefore, gender was not involved in the model as a command variable in succeeding data analysis.

Table 1: Effect size and repeated measures analysis of variance

\begin{tabular}{llll}
\hline & Gratitude & Benign envy & Malicious envy \\
\hline Cohen's d & -0.016 & 0.204 & 0.101 \\
Effect size (r) & -0.008 & 0.101 & 0.050 \\
F & 3.937 & 0.602 & 3.609 \\
$p$ & 0.048 & 0.438 & 0.058 \\
\hline
\end{tabular}

\subsection{Descriptive Statistics and Connections Analysis}

Table 2 imparted the descriptive information (means and standard deviations) and correlations among characteristic gratitude, $\mathrm{BE}$ and $\mathrm{ME}$ at two time points. As expected, at $\mathrm{T} 1$ and $\mathrm{T} 2$, trait gratitude, and $\mathrm{BE}$ were quite positively associated with each other, and trait gratitude and BE were actually negatively related to $\mathrm{ME}$. 
Table 2: Descriptive statistics and correlations for the major variables

\begin{tabular}{lllllll}
\hline & 1 & 2 & 3 & 4 & 5 & 6 \\
\hline 1. TGT1 & - & & & & \\
2. BET1 & $0.376^{* *}$ & - & & & \\
3. MET1 & $-0.418^{* *}$ & $-0.155^{* *}$ & - & & \\
4. TGT2 & $0.465^{* * *}$ & $0.232^{* *}$ & $-0.285^{* *}$ & - & & \\
5. BET2 & $0.314^{* *}$ & $0.415^{* *}$ & $-0.172^{* *}$ & $0.398^{* *}$ & - & \\
6. MET2 & $-0.267^{* *}$ & $-0.087^{* *}$ & $0.457^{* *}$ & $-0.333^{* *}$ & $-0.107^{* *}$ & - \\
M & 33.133 & 23.029 & 11.867 & 33.227 & 21.990 & 11.285 \\
SD & 5.771 & 4.750 & 5.966 & 5.832 & 5.431 & 5.578 \\
\hline Note: TG, trait gratitude; BE, benign envy; ME, malicious envy; TI, Time 1; T2, Time $2 *^{*} p<0.05, * * p<0.01, * * * p<0.001$. &
\end{tabular}

\subsection{Cross-Lagged Regression Models}

We examined the stability and cross-lagged effects among trait gratitude, BE, and ME. Cross-lagged effects refer to the prediction of one variable by the other, controlling for their stability over time. Summary fit indices for the four constructed models (Model 1-Model 4; see Fig. 1) were reported in Table 3. As showed in Table 3, all the models presented a good to exceptional fit according to the indicators. In addition, normalized steadiness and cross-lagged modulus were displayed in Table 4.

Table 3: Fit indicators for the four Models 1-4

\begin{tabular}{llllllllll}
\hline Model & $\chi^{2}$ & df & RMSEA & SRMR & CFI & TLI & Comparison & $\Delta \chi^{2}$ & $\Delta$ df \\
\hline Model 1 & 238.868 & 69 & 0.052 & 0.057 & 0.965 & 0.953 & & & \\
Model 2 & 224.514 & 67 & 0.051 & 0.051 & 0.967 & 0.955 & M1-M2 & 14.354 & 2 \\
Model 3 & 238.000 & 67 & 0.053 & 0.057 & 0.964 & 0.952 & M1-M3 & 0.868 & 2 \\
Model 4 & 222.513 & 65 & 0.052 & 0.051 & 0.967 & 0.954 & M1-M4 & 16.355 & 4 \\
\hline
\end{tabular}

Note: SRMR, standardized root mean squared residuals; RMSEA, root mean square error of approximation; CFI, comparative fit indicatrix; TLI, Tucker-Lewis indicatr.

Table 4: Overview of the normalized constancy and cross-lagged coefficient

\begin{tabular}{lllll}
\hline Model & Autoregressive path & $\beta$ & Cross-lagged path & $\beta$ \\
\hline 1 & TGT1 $\rightarrow$ TGT2 & $0.573^{* * *}$ & & \\
& BET1 $\rightarrow$ BET2 & $0.553^{* * *}$ & & \\
& MET1 $\rightarrow$ MET2 & $0.530^{* * *}$ & & $0.180^{* * *}$ \\
2 & TGT1 $\rightarrow$ TGT2 & $0.600^{* * *}$ & $\mathrm{TG}_{\mathrm{T} 1} \rightarrow \mathrm{BE}_{\mathrm{T} 2}$ & $-0.130^{* *}$ \\
& BET1 $\rightarrow$ BET2 & $0.436^{* * *}$ & $\mathrm{TG}_{\mathrm{T} 1} \rightarrow \mathrm{ME}_{\mathrm{T} 2}$ & \\
& MET1 $\rightarrow$ MET2 & $0.506^{* * *}$ & & -0.048 \\
& TGT1 $\rightarrow$ TGT2 & $0.605^{* * *}$ & $\mathrm{BE}_{\mathrm{T} 1} \rightarrow \mathrm{TG}_{\mathrm{T} 2}$ & -0.001 \\
& $\mathrm{BET} 1 \rightarrow$ BET2 & $0.548^{* * *}$ & $\mathrm{ME}_{\mathrm{T} 1} \rightarrow \mathrm{TG}_{\mathrm{T} 2}$ & \\
& $\mathrm{ME} \mathrm{T} 1 \rightarrow$ MET2 & $0.531^{* * *}$ & & $0.192^{* * *}$ \\
& $\mathrm{TGT} 1 \rightarrow$ TGT2 & $0.649^{* * *}$ & $\mathrm{TG}_{\mathrm{T} 1} \rightarrow \mathrm{BE}_{\mathrm{T} 2}$ & $-0.110^{* *}$ \\
& $\mathrm{BET} 1 \rightarrow$ BET2 & $0.419^{* * *}$ & $\mathrm{TG}_{\mathrm{T} 1} \rightarrow \mathrm{ME}_{\mathrm{T} 2}$ & -0.072 \\
& $\mathrm{MET} 1 \rightarrow$ MET2 & $0.507^{* * *}$ & $\mathrm{BE}_{\mathrm{T} 1} \rightarrow \mathrm{TG}_{\mathrm{T} 2}$ & 0.004 \\
\hline
\end{tabular}


First, the autoregressive model (Model 1) was created to examine the temporal constancy of each variable as time goes by. The results found that the model showed a good fit: $\chi_{(69, \mathrm{~N}=906)}^{2}=238.868, p<$ $0.001, \mathrm{RMSEA}=0.052, \mathrm{SRMR}=0.057, \mathrm{CFI}=0.965$, TLI $=0.953$ (see Table 3). As showing in Table 3, significant steadiness effects for all measures are found, indicating that these variables were relatively stable over time.

Second, the causation model from trait gratitude to two forms of envy (Model 2) was tested. In the model, we added the cross-lagged routes from trait gratitude at $\mathrm{T} 1$ to BE at T2 and ME at T2 based on Model 1. Model 2 also showed a good fit: $\chi_{(67, \mathrm{~N}=906)}^{2}=224.514, p<0.001$, RMSEA $=0.051$, SRMR $=$ $0.051, \mathrm{CFI}=0.967, \mathrm{TLI}=0.955$. The autoregressive routes remained significant and stable. And the results revealed that trait gratitude at $\mathrm{T} 1$ could positively forecast $\mathrm{BE}(\beta=0.180, p<0.001)$ at $\mathrm{T} 2$, and negatively forecast $\mathrm{ME}(\beta=-0.13, p<0.01)$ at $\mathrm{T} 2$. This indicated that trait gratitude could positively predict benign envy and negatively predict malicious envy over time.

Third, the reverse causation model (Model 3) was examined. In the model, we added reverse routes from $\mathrm{BE}$ and $\mathrm{ME}$ at $\mathrm{T} 1$ to trait gratitude at T2 to Model 1 . The model showed an acceptable fit: $\chi_{(67, \mathrm{~N}=}^{2}$ 906) $=238.000, p<0.001, \mathrm{RMSEA}=0.053, \mathrm{SRMR}=0.057, \mathrm{CFI}=0.964, \mathrm{TLI}=0.952$. The autoregressive routes in Model 3 remained prominent and permanent. However, the results directly indicated that all cross-lagged routes were non-significant. That is, $\mathrm{BE}$ and $\mathrm{ME}$ could not predict trait gratitude over time.

Finally, we tested the reciprocal causation model (Model 4), and found similar patterns of results to Model 2. The model displayed an acceptable fit: $\chi_{(65, \mathrm{~N}=906)}^{2}=222.513, p<0.001$, RMSEA $=0.052$, $\mathrm{SRMR}=0.051, \mathrm{CFI}=0.964, \mathrm{TLI}=0.952$. The findings found that gratitude at $\mathrm{T} 1$ could positively predict $\mathrm{BE}$ at T2 $(\beta=0.192, p<0.001)$ and could negatively predict ME at T2 $(\beta=-0.11, p<0.01)$, and other cross-lagged routes were not significant.

\subsection{Model Stability Analysis}

In order to further explore the influence of irrelevant variables on the model results, we controlled the two important demographic variables (gender and age), and found that the results of Model 4 are still stable: $\chi_{(60, \mathrm{~N}=906)}^{2}=74.119, p<0.001, \mathrm{RMSEA}=0.042, \mathrm{SRMR}=0.043, \mathrm{CFI}=0.979, \mathrm{TLI}=0.968$. The findings found that gratitude at T1 could positively predict BE at T2 $(\beta=0.166, p<0.001)$ and could negatively predict ME at T2 $(\beta=-0.185, p<0.05)$, while $\mathrm{BE}$ at $\mathrm{T} 1$ could not positively predict gratitude at $\mathrm{T} 2$ $(\beta=-0.013, p=0.802)$ and ME at T1 could not negatively predict gratitude at T2 $(\beta=-0.024, p=0.624)$.

In addition, considering that adolescence is a period of rapid physical and mental development, the study chose elementary school students and junior high school students as two different groups to construct Model 4 , and explored the stability of the research results in different stages. The two model displayed an acceptable fit, Model 4 in elementary school students (Model 4-a): $\chi^{2}{ }_{(41, \mathrm{~N}=906)}=47.704, p=0.219$, RMSEA $=0.019$, $\mathrm{SRMR}=0.025, \mathrm{CFI}=0.997, \mathrm{TLI}=0.995$; Model 4 in junior high school students (Model 4-b): $\chi^{2}(41, \mathrm{~N}=$ 906) $=63.119, p<0.05, \mathrm{RMSEA}=0.035, \mathrm{SRMR}=0.024, \mathrm{CFI}=0.991, \mathrm{TLI}=0.986$ ). Besides, according to Byrne's research [34], based on indicators such as basic parameter factor-loading, error variance and structural covariance equal, we compared the models between elementary school students and junior high school students. It turns out that there are differences in Model 4 between elementary school students and junior high school students $\left(\Delta \chi_{(45, \mathrm{~N}=906)}^{2}=199.769, p<0.001\right)$.

We further compare the path differences of the two models (Model 4-a, Model 4-b) based on the rule of $\mathrm{CRD}>1.96$ [35]. The results showed that the predictive effect of gratitude on malicious envy is different among elementary school students and junior high school students $(\mathrm{CRD}=2.803>1.96)$. The predictive effect is significantly higher in elementary school students $(\beta=-0.237, p<0.05)$ than in junior high school students $(\beta=-0.135, p<0.05)$. 
In sum, the outcomes revealed that characteristic gratitude at Time 1 could positively forecast $\mathrm{BE}$ at Time 2, and it could negatively forecast ME at Time 2. Furthermore, there was no absolute evidence for the reversal or mutual relationship between peculiarity gratitude and BeMaS.

\section{Discussion}

To explore the predictive causality relationship between gratitude and benign/malicious envy, the present research conducted a longitudinal study between gratitude and benign/malicious envy in Chinese adolescents. Our findings revealed that gratitude was a certain positive predictor of benign envy and a dependable negative predictor of malicious envy in Chinese adolescents, which supported Hypothesis 1. Furthermore, there was no indication for the reversal or mutual relationship between gratitude and benign/malicious envy. The study extended the correlated theories about the link between gratitude and benign/malicious envy, and provided empirical evidence for how to exert the positive effect of envy and gratitude among adolescents.

Specifically, these results are consistent with previous cross-sectional studies reporting the relation between gratitude and BeMaS among undergraduates [14,15]. However, it did not consider whether there was a reverse or reciprocal relationship between gratitude and BeMaS. In addition, concerning the causal link between gratitude and envy has also been indirectly supported by former experimental research. For example, Lambert et al. [36] found that experimentally induced gratefulness resulted in low materialism, which is closely related to envy, in a high gratitude condition in undergraduates. Besides, Mao et al. [19] used the scenario method found that context gratitude inhibits context envy and circumstance gratitude takes a partial mediating function between trait gratitude and context envy in university students. But these experimental studies do not distinguish between benign and malicious envy. What's more, the above studies are not concerned about adolescents. In summary, the present research extends previous findings to the adolescent population, provides further evidence for the temporal directionality of the link between gratitude and BeMaS, and provides practical support for envy and gratitude interventions among Chinese adolescents.

So why does gratitude have different effects on different kinds of envy? The broaden-and-build theory provides a perspective for understanding the causal relationship between gratitude and benign/malicious envy. Specifically, according to the broaden-and-build theory, gratitude, as a positive emotion, expands the individual's thoughts and builds their lasting positive resources [9], which leads to a high sense of control and deservingness in the fact of upward social comparison, and then causes more benign envy [13]. In contrast, people with low gratitude result in narrow vision and lack of resources, and lead to a higher sense of unfairness, which contributes to malicious envy in upward social comparison [13]. Therefore, gratitude could forecast benign envy positively and malicious envy negatively.

In addition, benign/malicious envy did not predict gratitude over time, which did not support Hypothesis 2. This suggested that there was no bi-directional liaison between gratitude and benign/malicious envy. That is to say, gratitude would affect the change of benign/malicious envy, but not vice versa. Thus, benign/ malicious envy is not a predictive factor for gratitude. Gratitude may appear earlier than envy as a social emotion, at least in the context of Chinese culture. Both benign envy and malicious envy lead to people notice that they lack while others have [37], instead of focusing on what they have, such as gratitude [4]. However, there may be other valuable factors, which react to gratitude. For example, a secure style is probably critical for gratefulness, no matter occurrence or development [38,39].

The current research also has some limitations. First, the current work did not explore the possible mechanism between gratitude and benign/malicious envy. Future research should explore the psychological mechanism underlying the link between gratitude and envy, such as social support and other potential variables. Second, the data relied on self-report measurement, thus social desirability bias might exist. Future studies can carry out experimental studies on situational gratitude and benign/ 
malicious envy. Third, although the total sample size of this study is considerable, the sample size is limited to Chinese adolescents. Besides, there are some measurement deviations because children may not fully understand some items of gratitude and envy scales. The stability and applicable population range of the study results need to be tested. Future studies can consider the reliability of the results in different populations.

In summary, the current study explored the predictive causality link between gratitude and benign/ malicious envy from a longitudinal perspective. Firstly, the findings provide further evidence for the temporal directionality of the association between gratitude and benign/malicious envy. At the same time, this study also had some practical significance in gratitude interventions that reduce the negative influence of envy among adolescents. Previous studies have found that gratitude interventions could alleviate negative emotions and improve personal wellbeing among adolescents [40,41]. For instance, the educators could add gratitude into existing programs (e.g., character education), which may motivate students to focus on their beautiful life experiences [42].

Acknowledgement: The authors are grateful for the support and grant funding contributed by Department of Education Project of Hunan Province of China (Grant No. 2019291174).

Funding Statement: This work was supported by Department of Education Project of Hunan Province of China (Grant No. 2019291174).

Conflicts of Interest: The authors declare that they have no conflicts of interest to report regarding the present study.

\section{References}

1. Petrocchi, N., Couyoumdjian, A. (2016). The impact of gratitude on depression and anxiety: The mediating role of criticizing, attacking, and reassuring the self. Self and Identity, 15(2), 191-205. DOI 10.1080/15298868.2015.1095794.

2. Rash, J. A., Matsuba, M. K., Prkachin, K. M. (2011). Gratitude and well-being: Who benefits the most from a gratitude intervention?. Applied Psychology: Health and Well-Being, 3(3), 350-369. DOI 10.1111/j.1758-0854.2011.01058.x.

3. Simons, M., Lataster, J., Peeters, S., Reijnders, J., Janssens, M. et al. (2020). Sense of abundance is associated with momentary positive and negative affect: An experience sampling study of trait gratitude in daily life. Journal of Happiness Studies, 21(6), 2229-2236. DOI 10.1007/s10902-019-00181-z.

4. McCullough, M. E., Emmons, R. A., Tsang, J. A. (2002). The grateful disposition: A conceptual and empirical topography. Journal of Personality and Social Psychology, 82(1), 112-127. DOI 10.1037/0022-3514.82.1.112.

5. Yang, K., Yan, W., Jia, N., Wang, Q., Kong, F. (2020). Longitudinal relationship between trait gratitude and subjective well-being in adolescents: Evidence from the bi-factor model. The Journal of Positive Psychology, 16(6), 802-810. DOI 10.1080/17439760.2020.1818812.

6. Poelker, K. E., Gibbons, J. L., Maxwell, C. A., Elizondo-Quintanilla, I. L. (2017). Envy, gratitude, and well-being among Guatemalan adolescents with scarce economic resources. International Perspectives in Psychology, 6(4), 209-226. DOI 10.1037/ipp0000076.

7. van de Ven, N., Zeelenberg, M., Pieters, R. (2009). Leveling up and down: The experiences of benign and malicious envy. Emotion, 9(3), 419-429. DOI 10.1037/a0015669.

8. Sterling, C., van de Ven, N., Smith, R. H. (2016). The two faces of envy: Studying benign and malicious envy in the workplace. In: Smith, R. H., Merlone, U., Duffy, M. K. (Eds.), Envy at Work and in Organizations: Reasearch, theory, and pplitions. pp. 57-84. New York: Oxford University Press.

9. Fredrickson, B. L. (2004). Gratitude, like other positive emotions, broadens and builds. In: Emmons, A. McCullough, M. E. (Eds.), The psychology of gratitude, pp. 145-166. New York: Oxford University Press.

10. Tian, L., Chu, S., Huebner, E. S. (2016). The chain of relationships among gratitude, prosocial behavior and elementary school students' school satisfaction: The role of school affect. Child Indicators Research, 9(2), 515-532. DOI 10.1007/s12187-015-9318-2. 
11. Kong, F., Yang, K., Yan, W., Li, X. (2021). How does trait gratitude relate to subjective well-being in Chinese adolescents? the mediating role of resilience and social support. Journal of Happiness Studies, 22(4), 16111622. DOI 10.1007/s10902-020-00286-w.

12. Lin, C. C. (2016). The roles of social support and coping style in the relationship between gratitude and well-being. Personality \& Individual Differences, 89, 13-18. DOI 10.1016/j.paid.2015.09.032.

13. van de Ven, N., Zeelenberg, M., Pieters, R. (2012). Appraisal patterns of envy and related emotions. Motivation and Emotion, 36(2), 195-204. DOI 10.1007/s11031-011-9235-8.

14. Xiang, Y., Chao, X., Ye, Y. (2018). Effect of gratitude on benign and malicious envy: The mediating role of social support. Frontiers in Psychiatry, 9(139), 1-7. DOI 10.3389/fpsyt.2018.00139.

15. Xiang, Y., Yuan, R. (2020). Why do people with high dispositional gratitude tend to experience high life satisfaction? A broaden-and-build theory perspective. Journal of Happiness Studies, 22(6), 1-14. DOI 10.1007/ s10902-020-00310-z.

16. Schoeck, H. (1969). Envy: A theory of social behavior. New York: Har-Court, Brace, and World. DOI 10.2307/ 1059904.

17. Klein, M. (1957). Envy and gratitude: A study of unconscious forces. Oxford, UK: Basic Books.

18. Froh, J., Emmons, R., Card, N., Bono, G., Wilson, J. (2011). Gratitude and the reduced costs of materialism in adolescents. Journal of Happiness Studies, 12(2), 289-302. DOI 10.1007/s10902-010-9195-9.

19. Mao, Y., Zhao, J., Xu, Y., Xiang, Y. (2020). How gratitude inhibits envy: From the perspective of positive psychology. PsyCh Journal, 10(3), 384-392. DOI 10.1002/pchj.413.

20. Solom, R., Watkins, P. C., McCurrach, D., Scheibe, D. (2016). Thieves of thankfulness: Traits that inhibit gratitude. Journal of Positive Psychology, 12(2), 120-129. DOI 10.1080/17439760.2016.1163408.

21. Dinić, B. M., Branković, M. (2021). Cross-cultural comparison of the benign and malicious envy scale (BeMaS) across serbian and US samples and further validation. European Journal of Psychological Assessment, 1-12. DOI 10.1027/1015-5759/a000643.

22. Bartlett, M. Y., Valdesolo, P., Arpin, S. N. (2020). The paradox of power: The relationship between self-esteem and gratitude. The Journal of Social Psychology, 160(1), 27-38. DOI 10.1080/00224545.2019.1601609.

23. Krizan, Z., Johar, O. (2012). Envy divides the two faces of narcissism. Journal of Personality, 80(5), 1415-1451. DOI 10.1111/j.1467-6494.2012.00767.x.

24. Watkins, P. C. (2014). Gratitude and the Good Life. Dordrecht: Springer.

25. World Health Organization (1999). Programming for adolescent health and development. Report of a WHO/ UNFPA/UNICEF Study Group on Programming for Adolescent Health. World Health Organization.

26. Kong, F., Ding, K., Zhao, J. (2015). The relationships among gratitude, self-esteem, social support and life satisfaction among undergraduate students. Journal of Happiness Studies, 16(2), 477-489. DOI 10.1007/ s10902-014-9519-2.

27. Xiang, Y., Zhao, J., Li, Q., Zhang, W., Dong, X. et al. (2019). Effect of core self-evaluation on mental health symptoms among Chinese college students: The mediating roles of benign and malicious envy. Psychiatric Annals, 49(6), 277-284. DOI 10.3928/00485713-20190508-01.

28. Lange, J., Crusius, J. (2015). Dispositional envy revisited: Unraveling the motivational dynamics of benign and malicious envy. Journal of Personality and Social Psychology, 41, 284-294. DOI 10.1177/0146167214564959.

29. Dong, X., Xiang, Y., Zhao, J., Li, Q., Zhao, J. et al. (2019). How mindfulness affects benign and malicious envy: From the perspective of the mindfulness reperceiving model. Scandinavian Journal of Psychology, 61(3), 436442. DOI 10.1111/sjop.12596.

30. He, N., Xiang, Y. (2021). How child maltreatment impacts internalized/externalized aggression among Chinese adolescents from perspectives of social comparison and the general aggression model. Child Abuse \& Neglect, 117, 105024. DOI 10.1016/j.chiabu.2021.105024.

31. Hu, L. T., Bentler, P. M. (1998). Fit indices in covariance structure modeling: Sensitivity to underparameterized model misspecification. Psychological Methods, 3(4), 424-453. DOI 10.1037//1082-989X.3.4.424. 
32. Davey, A. (2009). Statistical power analysis with missing data: A structural equation modeling approach. New York, NY: Routledge.

33. Zhou, H., Long, L. (2004). Statistical remedies for common method biases. China Journal of Advances in Psychological Science, 2004, 12(6), 942-950.

34. Byrne, B. (2001). Structural equation modeling with amos: basic concepts, applications and programming. New Jersey: Lawrence Erlbaum Associates.

35. Arbuckle, J. L. (2003). AMOS 5.0 update to the AMOS user's guide. Chicago, IL: Smallwaters.

36. Lambert, N. M., Fincham, F. D., Stillman, T. F., Dean, L. R. (2009). More gratitude, less materialism: The mediating role of life satisfaction. Journal of Positive Psychology, 4(1), 32-42. DOI 10.1080/17439760802216311.

37. Smith, R. H., Kim, S. H. (2007). Comprehending envy. Psychological Bulletin, 133(1), 46-64. DOI 10.1037/00332909.133.1.46.

38. Lystad, A., Watkins, P., Sizemore, L. (2005). The importance of attachment processes to gratitude. Presentation to the 85th Annual Convention of the Western Psychological Association, Portland, OR.

39. Konkler, J. (2014). Effect of priming attachment styles on gratitude in close relationships (Master Thesis). Eastern Washington University, Washington.

40. Froh, J. J., Kashdan, T. B., Ozimkowski, K. M., Miller, N. (2009). Who benefits the most from a gratitude intervention in children and adolescents? Examining positive affect as a moderator. Journal of Positive Psychology, 4(5), 408-422. DOI 10.1080/1743976090292464.

41. Khanna, P., Singh, K. (2016). Effect of gratitude educational intervention on well-being indicators among north Indian adolescents. Contemporary School Psychology, 20(4), 305-314. DOI 10.1007/s4688-016-0087-9.

42. Caleon, I. S., King, R. B., Tan, J. P. L., Low, M., Tan, C. S. et al. (2017). Nurturing grateful and connected twentyfirst century learners: Development and evaluation of a socially oriented gratitude intervention. Asia Pacific Journal of Education, 37(4), 567-581. DOI 10.1080/02188791.2017.1386091. 